\title{
"DANÇAR DÓI, MAS DÓI MAIS QUANDO ESTOU PARADA": REFLEXÕES SOBRE O CORPO NA DANÇA
}

\author{
"DANCING HURTS, BUT IT HURTS MORE WHEN I'M STOPPED”: REFLECTIONS \\ ON THE BODY IN DANCE
}

"BAILAR DUELE, PERO DUELE MÁS CUANDO ME QUEDO QUIETA": REFLEXIONES SOBRE EL CUERPO EN LA DANZA

\section{Vanda Nascimento*}

\section{Palavras chave:} Dança.

Arte.

Corpo humano.
Resumo: A dança, enquanto arte performativa, utiliza o corpo como instrumento fundamental do discurso artístico e como forma de comunicação e relação com o mundo. Partindo-se do facto do bailarino ser detentor do corpo que dá corpo à dança, entendemos (re)visitar autores aos quais reconhecemos afinidades e partilhar algumas reflexões sobre o corpo, a sua importância, significância e inscrição nos vastos domínios da dança. Assumimos o corpo enquanto instrumento "afinado" de um bailarino que é capaz de ter domínio sobre esse corpo e que tem competências para criar um novo vocabulário de movimento, respondendo de forma mais eficaz e concordante com a pluralidade e mutabilidade das solicitações do mercado da dança.

Keywords:

Dance.

Art.

Human body.

Palabras clave:

Baile.

Arte.

Cuerpo humano.
Abstract: As a performance art, dance uses the body as a core instrument of artistic discourse and as a way to communicate and relate to the world. Starting from the fact that dancers hold the bodies that embody dance, we intend to (re)visit authors with whom we share affinities and reflections about the body, its importance, significance and inscription in the vast domains of Dance. We take the body as the "tuned" instrument of a dancer who is able to master that body and who has the skills to create a new vocabulary for movement, thus responding more effectively and in accordance with the plurality and changeability of Dance market requests.

Resumen: La danza como arte de la performance, utiliza el cuerpo como instrumento fundamental del discurso artístico y como medio de comunicación y relación con el mundo. Partiendo del hecho de que el bailarín está en posesión del cuerpo que da cuerpo a la danza, (re)visitamos autores con los cuales reconocemos afinidades y compartimos algunas reflexiones sobre el cuerpo, su importancia, significado y registro en los vastos dominios de la danza. Asumimos el cuerpo como un instrumento "afinado" de un bailarín que es capaz de tener dominio sobre ese cuerpo y que tiene competencias para crear un nuevo vocabulario del movimiento, respondiendo de manera más eficaz y de acuerdo con la pluralidad y la mutabilidad de las demandas del mercado de la danza.
*Instituto Politécnico de Lisboa. Escola Superior de Dança Lisboa, Portugal. E-mail: vnascimento@esd.ipl.pt

Recebido em: 03-02-2017 Aprovado em: 10-06-2017

(c) (1) (8) Licence 


\section{INTRODUÇÃO}

A dança, enquanto arte performativa, utiliza o corpo como instrumento fundamental do discurso artístico e como forma de comunicação e relação com o mundo, ou seja, "[...] a Dança na sua generalidade ao pretender impressionar artisticamente passa pelas seguintes funções: criar intencionalmente, comunicar expressivamente e observar contemplativamente" (BATALHA; XAREZ, 1999, p. 78).

A nossa prática profissional no ensino da dança construída ao longo de vários anos de lecionação de disciplinas de caráter mais prático, e a vontade de sistematizar o conhecimento construído e as partilhas acumuladas, levou-nos a (re)visitar autores aos quais se reconhece afinidades permitindo, numa análise compreensiva desses contributos, produzir algumas reflexões sobre o corpo, a sua significância e inscrição nos vastos domínios da dança.

De forma a circunscrevermos a abrangência do discurso sobre dança e sobre o corpo, adotaremos, como referencial, o conceito e a dimensão da dança teatral que definiu Fazenda:

A dança teatral tem como propósito a construção de uma performance, por parte de um grupo de intérpretes seleccionados de acordo com expectativas definidas por motivações artísticas e pressupostos estéticos determinados, para ser vista por um grupo de pessoas - os espectadores ou público (FAZENDA, 2012, p. 43).

A opção de olharmos o corpo no contexto da dança teatral justifica-se por ser este o lugar privilegiado em que o bailarino se vai expor com o seu principal instrumento de trabalho: o corpo, apresentando-se este, designadamente, como o redator, o suporte e o texto (SIBONY, 1995).

Sendo o bailarino o sujeito detentor do corpo, objeto de reflexão, entendemos importante, antes de aprofundar a temática, rever algumas das designações utilizadas para 0 definir (o bailarino), procurando, com isso, também, contextualizar o leitor sobre o objecto de estudo, ou seja: que corpo? que bailarino?

A designação consagrada na Classificação Portuguesa das Profissões 2010, publicada pelo Instituto Nacional de Estatística (INE), no grande grupo 2, mais especificamente no subgrupo 2653.1, onde descreve as competências do bailarino:

[...] compreende as tarefas e funções do bailarino que consistem, particularmente, em: Ensaiar e executar os passos, as figuras, as expressões e os encadeamentos dum bailado, como solista ou como membro duma companhia de dança, de espectáculos de circo e outro tipo de diversão; Executar coreografias em espectáculos realizados em estabelecimentos de diversão (INSTITUTO NACIONAL DE ESTATÍSTICA, 2011, p. 184).

Considerando que esta designação é tão generalista como redutora, procurámos recolher outras visões e outras designações. O Instituto para a Qualidade na Formação (IQF), designa o bailarino como o agente que,

[...] executa e interpreta, a solo ou em grupo, sequências de movimento de uma obra coreográfica destinada a apresentação pública, usando o corpo e os seus elementos, bem como o respectivo movimento para exprimir e comunicar sentimentos, ideias, narrativas, estados de espírito (INSTITUTO PARA A QUALIDADE NA FORMAÇÃO, 2006, p. 64).

Para Macara (1994), a denominação bailarino(a), no sentido lato, designa não apenas o profissional de dança, mas todo aquele que se dedica regularmente a atividades de dança, 
ou se apresenta em público a dançar. No que diz respeito ao tipo de atuação (profissional ou amador), Monteiro (1995) qualifica o bailarino profissional como aquele que assume, como atividade exclusiva e remunerada, a dança.

Em abono do que atrás se refere, defendemos a designação de bailarino com uma maior abrangência e com um significado mais amplo em que a escolha do corpo e do movimento do corpo como ponto de relação com o mundo, e como veículo de saber, pensamento e modo de expressão, se evidenciam. Registamos, assim, pela clarividência do seu pensamento contemporâneo, as palavras de Louppe (2012, p. 69) "[...] ser bailarino é escolher o corpo e o movimento do corpo como campo de relação com o mundo, como instrumento de saber, de pensamento e de expressão". Assumimos aqui a relação indissociável do bailarino e do seu corpo, enquanto instrumento primeiro e prioritário da sua essência e existência.

Extrapolamos, nesta reflexão, a significância da dança, enquanto "[...] expressão - através de movimentos corporais organizados de forma significativa - de conceitos que transcendem a capacidade de o indivíduo os exprimir pela razão e pelo intelecto" (MARTIN, 1991, p. 94), sustentando-se a ideia de que um bailarino de qualidade passa, indiscutivelmente, por processos de aprendizagem, expressão e representação em que o corpo é o principal agente e defende-se como importante a prática regular e sistemática das técnicas de dança. Em concordância com Foster (1992) quando observa que "[...] conheço o corpo somente através da sua resposta aos métodos e técnicas utilizados para o cultivar" (FOSTER, 1992, p. 480 , tradução nossa)

\section{CORPO ENQUANTO INSTRUMENTO}

As palavras de José Limón, citadas em Louppe (2012, p. 69), em que afirma "Feliz 0 bailarino que dispõe da ferramenta mais eloquente e milagrosa de todas: 0 corpo humano" serviram de mote para o objetivo deste ensaio: (re)visitar autores aos quais se reconhece afinidades construídas ao longo de vários anos de lecionação de disciplinas de caráter mais prático e partilhar, com base numa análise compreensiva desses contributos, algumas reflexões sobre o corpo, a sua significância e inscrição nos vastos domínios da dança.

$\mathrm{Na}$ perspetiva da dimensão sociocultural do corpo, considerámos incontornável convocar o antropólogo Marcel Mauss - pioneiro na referência às aprendizagens culturais do corpo e ao que designa como "técnicas do corpo" -, cujo conceito permite revelar os modos como esse instrumento, que é simultaneamente físico, mecânico e químico, é adaptado e se vai adaptando ao, e no, contexto social em que vive. 0 seu discurso transmite uma visão do corpo enquanto instrumento e veículo de comunicação e relação com o mundo. Para este autor "[...] o corpo é o primeiro e o mais natural instrumento do homem. Ou mais exactamente, sem falar de instrumento, o primeiro e mais natural objecto técnico, e ao mesmo tempo o meio técnico do homem, é o seu corpo" (MAUSS, 2015, p. 407).

De um outro ponto de vista e no entendimento da dança, no sentido mais lato, como uma expressão artística em que o corpo é o instrumento fundamental e prioritário, recordámos o que expôs Ribeiro:

Um corpo não é uma entidade abstracta, um receptáculo onde se podem colocar atributos tais como alto, baixo, forte, magro; não é uma esfera a que se circunscreve o ser num determinado tempo, mas é uma energia onde se inscrevem circulações, 
substâncias, forças, pigmentações, comportamentos resultantes de treinos, de técnicas e de linguagens a que está permanentemente sujeito (RIBEIRO, 1997, p.7).

Continuando a reflexão e partilha sobre a significância do corpo na dança observamos, no espaço da formação de bailarinos, e na perspetiva de alguns autores (GLASSTONE, 1977; LAWSON, 1988; KASSING; JAY, 1998; WARBURTON, 2002, MINDEN, 2005), a importância que assume o corpo no que se refere aos requisitos mínimos necessários de coordenação e senso natural de ritmo mas, sobretudo, requisitos físicos adequados para prática da dança. Entre os mais importantes estão "umas costas fortes, direitas, e ainda com mobilidade; pés flexíveis; articulações móveis; um tendão de Aquiles flexível; pernas retas e a capacidade para girar as pernas livremente no encaixe do quadril aumentando assim a amplitude de movimento dos bailarinos" (GLASSTONE, 1977, p. 11, tradução nossa).

Para responder às exigências do trabalho, os indivíduos que optarem por uma carreira profissional como bailarinos utilizarão o corpo como instrumento de trabalho e forma de expressão em toda a sua complexidade e grandiosidade, mantendo esse mesmo corpo treinado e adestrado ao longo de toda a sua vida ativa. A esse corpo se exigirão, muitas vezes, altas performances, tal como se de um instrumento afinado se tratasse.

Esta "afinação" e excecionalidade encontram-se patentes na qualificação que proferiu Ribeiro (1994) quando considerou que "Florence Griffith-Joyner, as ginastas romenas, ou os La La La Human Steps são corpos Hi-Fi. São corpos de alta-fidelidade na execução das suas performances" (RIBEIRO, 1994, p. 10).

Ainda propósito da particularidade destes corpos, e consequentemente do lugar destacado que detêm, o mesmo autor afirmou que "[...] a utilização destes corpos Hi-Fi serviu nas Artes do Corpo uma certa ideia de sublime que lhes permitiu conquistarem um lugar nobre junto das tradicionais e reconhecidas artes" (RIBEIRO, 1994, p. 10). Podemos, com alguma facilidade, visualizar a excepcionalidadedestes corpos

[...] ao assistirmos à performance de uma bailarina em pontas; ao observarmos 0 impressionante controlo da amplitude articular dos membros inferiores, de muitos bailarinos, muitas vezes rondando os $180^{\circ}$, em equilíbrios perfeitos em qualquer grande pose de dança - arabesques, atitudes ou écartés; nas quedas (falls), depois de saltos que desafiam a gravidade ou, nas inúmeras pirouettes e voltas com o corpo na vertical, em contração ou em tilts, dominando o equilíbrio num perfeito 'desequilíbrio controlado' (NASCIMENTO, 2010, p. 73).

Depreendemos, pelo atrás referido, que a prática da dança exigirá, assim, dos seus praticantes, condições físicas específicas e "ideais", dentro do contexto de determinado estilo e percurso pretendido. Encontramos eco desta afirmação nas palavras de Haskell (1955, p. 39), ao observar que "os bailarinos diferem imensamente no físico, tipo e temperamento, mas há atributos de que todos necessitam. O primeiro é um físico conveniente". Encontramos sustentação na primazia da afirmação quando falamos de um corpo apto a cumprir com qualquer programa de treino em dança - previsto no plano de estudos de instituições onde se faz a formação de bailarinos - integrando as componentes: físicas, psicológicas, biológicas e coreográficas apresentadas por Xarez (2013) e que se prevê terem como finalidade "a melhoria contínua do rendimento e da performance artística, a prevenção de lesões e o alargamento das carreiras dos bailarinos profissionais" (XAREZ, 2013, p. 10). 
Neste sentido, poderemos entender o papel e o "peso" que o corpo, enquanto instrumento, terá na vida dos(as) bailarinos(as) cuja escolha de uma carreira se inicia, normalmente, por volta dos 9/10 anos, em Portugal no $5 . .$. ano do ensino básico/início do $2 .{ }^{\circ}$ ciclo da escolaridade obrigatória.

\section{CORPO NA PERFORMANCE}

A avaliação dos requisitos para a prática da dança, quando se almeja a via profissional, realiza-se através de provas/audições que, em contexto académico, se compõem de várias provas cujo objetivo é a seleção prévia de candidatos com aptidões e condições recomendáveis para a prática da dança.

Estas provas baseiam-se em critérios definidos consoante as características, objetivos e planos de estudo de cada escola, tendo em vista as necessidades e capacidades dos selecionados, numa perspetiva de poderem construir/desenvolver uma carreira de bailarino(a).

Comum à maioria das escolas de formação de bailarinos em todo o mundo, esta prática pode assumir outras designações, como, por exemplo: provas de avaliação de capacidades, provas de seleção, exame classificatório, provas de aptidão, entre outras.

Importa ressalvar que, em contexto profissional, também se realizam audições ou castings, mas com objetivos diferentes.

As audições para companhias profissionais, grupos organizados ou projetos pontuais têm como objetivo selecionar bailarinos que possuam determinadas qualidades físicas, técnicas e interpretativas mas, também, capacidade de improvisação que satisfaçam os objetivos da companhia, do coreógrafo ou do projeto em criação. As entrevistas que Nielsen e Cilento (1984) realizaram aos principais responsáveis pelas audições em diferentes companhias americanas, questionando-os sobre as razões que motivaram as suas escolhas, são ilustrativas da abrangência dos critérios de seleção referidos.

A procura de "corpos proficientes" por parte das companhias de dança é fácil de verificar numa rápida busca online de anúncios de audições para companhias de dança de todo o mundo. A título de exemplo transcrevemos um anúncio de audição da La La La Human Steps: "AUDIÇÃO APENAS POR CONVITE: A La La La Human Steps procura bailarinos profissionais masculinos e femininos com um alto nível de formação técnica em balé" (NETWORKDANCE, 2016, tradução e grifo nosso).

Independentemente da área onde desenvolverá a sua profissão futura (com cariz mais clássico ou mais contemporâneo; numa instituição mais formal ou em projetos independentes ou pontuais), e tendo como objetivo a formação de bailarinos, as escolas de ensino artístico especializado da dança terão de exigir muito mais dos seus praticantes.

Considerando que a prática diária da dança - nas suas várias vertentes - dura toda uma vida ativa, que os bailarinos profissionais fazem diariamente aula(s) de técnica(s) de dança, para além dos ensaios e respetivos espetáculos, e que a idade de aposentação dos bailarinos é aos 55 anos (tendo como referência a Companhia Nacional de Bailado que assim o prevê nos termos da legislação portuguesa), estaremos a falar de muitas horas de "utilização" do seu instrumento, o corpo, com todas as consequências que daí possam advir. 
A este propósito evocamos a peça que a Companhia Nacional de Bailado (CNB) estreou, mundialmente, a 5 de fevereiro de 2015, intitulada A perna esquerda de Tchaikovski: Peça para uma bailarina e um pianista, que reflete muito do que atrás se refere. Essa peça, escrita e dirigida por Tiago Rodrigues (ator, encenador e dramaturgo português), em diálogo permanente com música original e ao vivo de Mário Laginha (compositor e pianista português), desenvolve-se em torno da memória de um corpo que está prestes a abandonar a dança e remete-nos para as memórias que se encontram inscritas no corpo da intérprete:

[...] as suas primeiras coreografias no quarto da sua infância, até ao último espetáculo de despedida [...] as suas rotinas, o seu horário de trabalho, as suas lesões e cirurgias, os aplausos memoráveis e os coreógrafos que a marcaram. Os bons e os maus momentos. As cicatrizes malignas e também as benignas (RODRIGUES, 2015, p.11).

Esta peça, dançada e interpretada pela própria Barbora Hruskova, bailarina da CNB, revisita a sua carreira, e as marcas que a vida de bailarina traçou no seu corpo espelham, de forma profunda e na primeira pessoa, o que atrás se refere: "cada dor no meu corpo, corresponde a um espectáculo de dança. Já danço há mais de 30 anos. [...]. Já fiz as contas e tenho a certeza de que já passei mais horas da minha vida a dançar do que a dormir" (RODRIGUES, 2015, p.11).

Dando corpo à reflexão que se vem apresentando sobre o corpo na dança, transcrevemos as palavras de Tiago Rodrigues constantes da folha de sala do espetáculo:

[...] Desejamos, também, mostrar ao público aquilo que a dança clássica obsessivamente esconde: 0 trabalho infernal que está por trás da beleza etérea do ballet. A disciplina militar, a dedicação que é quase devoção, a compulsiva busca da perfeição, as privações, a constante autocrítica. E sim, o prazer (RODRIGUES, 2015, p.11).

Apesar de ancoradas no âmbito da dança clássica considera-se, no entanto, que estas memórias seriam eventualmente a "reprodução" da memória do corpo e da vida de muitos/as bailarinos(as). Como no mesmo texto afirma: "traduzindo a história singular de Barbora para 0 palco, apontamos a poética que pode aplicar-se a qualquer bailarina que se despede da dança" (RODRIGUES, 2015, p.11).

Outra "visão" reportada ao âmbito da dança clássica (bailado), mas que se entende transversal e aplicável a outros tipos e estilos de manifestação de dança e aos vários corpos que a habitam, é a sublinhada por Lourenço,

O bailado é, de facto, uma arte que vive dos corpos que the dão corpo, da humanidade dos seres que materializam esta arte, que a transformam em experiência real, imediata, emotiva, inesquecível. [...] a dança não é materializada por intermédio de nada que não seja diretamente o próprio corpo humano (LOURENÇO, 2014, p. 29).

\section{O CORPO MAPEADO}

[...] a dança, explora uma multiplicidade de corpos, cada um contendo como que uma partitura secreta, um imenso leque de possibilidades e de tonalidades poéticas, algo a que Laban designa como 'assinatura corporal' (LOUPPE, 2012, p. 85). 
Ao olharmos para um corpo detentor de conhecimento e domínio das técnicas, capaz de mover-se de forma culturalmente relevante, estaremos, de acordo com o enquadramento anterior, a observar um corpo "tecnicamente mapeado", ou seja, com a capacidade de explorar os seus vastos domínios físicos, psicológicos, espácio-temporais e expressivos, "navegando", com conhecimento, pelas fronteiras que se entende como limite ou especialização.

Para a concretização deste "mapeamento" e a "afinação" do respetivo instrumento (o corpo), julgámos importante que este se verifique no período de formação. Ou seja, "a formação artística deverá acompanhar o mercado de trabalho, em particular, as novas conceções coreográficas e as novas visões dos corpos e das suas potencialidades na performance" (FERNANDES; GARCIA, 2015, p. 45).

Neste sentido, recentramos o discurso sobre importância do corpo na formação de bailarinos, destacando a relevância que uma avaliação atenta e abrangente do(a) jovem que vai iniciar uma carreira de bailarino(a), cujo principal instrumento de trabalho será, como já se evidenciou, o seu corpo.

A precocidade na escolha da dança como profissão é uma constatação e 0 estabelecimento do limite de idade para a entrada nas escolas vocacionais é uma prática assumida pela maioria das escolas de formação de bailarinos em todo o mundo e, no caso de Portugal, encontra-se consagrada na legislação vigente que se transcreve: "Nos ensinos da música e da dança há uma educação artística e um adestramento físico específicos, que têm de iniciar-se muito cedo, na maior parte dos casos até cerca dos 10 anos" (PORTUGAL, 1983, p. 2388).

Face a esta realidade - precocidade na escolha por um lado e seleção por outro - é indispensável, concordando ou não com estas práticas, que todos os que têm a responsabilidade de avaliar os futuros estudantes de dança tenham a consciência de que, apesar de muito relevante, a avaliação das "condições físicas" não deixa de ser um risco, já que é feita numa idade (pré-adolescência, início da puberdade) em que, por um lado, o desenvolvimento físico da criança não está completo e definido, podendo revelar-se, desta forma, uma surpresa (positiva ou negativa); por outro lado, estas crianças não possuem, ainda, maturidade psicológica para decidir a sua "vocação profissional". Como afirmou Fonseca (1993, p. 49) "[...] o desenvolvimento vocacional surge como resultado de uma interacção dinâmica, que ocorre ao longo de todo o ciclo de vida, entre um indivíduo em desenvolvimento e um contexto em permanente transformação".

Se uma avaliação objetivada para o aspeto físico é imprescindível, como referido, há contudo outros aspetos, não menos importantes, a considerar nesta avaliação:

Muito poucas pessoas possuem todos esses atributos, razão pela qual é tão importante para os alunos de balé ter outras três qualidades: determinação, clareza de pensamento e humildade. A humildade para ser autocrítico sobre os seus próprios defeitos; clareza de pensamento para entender o que pode ser feito para remediá-los; e a determinação para perseverar (GLASSTON, 1977, p. 11, tradução nossa).

Os estudos de Warburton (2002) e, mais recentemente, de Walker, Nordin-Bates e Redding (2010) a propósito da seleção de jovens "potenciais talentos" destacam como factores importantes na avaliação não só os aspetos físicos, expressivos e psicológicos (centrados no indivíduo), mas outros relacionados com o envolvimento social e o tipo de experiências a que as crianças e os jovens têm acesso. 
Cogumbreiro (2002)1', na sua preleção durante o I Fórum da Dança, realizado em Tomar, apresentou, em linha com Taylor e Taylor (1995), as características e a definição exaustiva dos diferentes critérios e parâmetros para cada um dos aspetos a ter em consideração ao selecionarse candidatos para o ensino especializado, cumprindo com as formalidades de "avaliar os pré-requisitos físicos: morfo-estruturais (definição do somato-tipo) e capacidades motoras, e os pré-requisitos psicológicos: motivação, autoconfiança, intensidade e concentração" (COGUMBREIRO, 2002, p.2)2.

Acrescentando ao que já foi descrito sobre a necessidade e importância de prérequisitos, há que ter em conta que, apesar das "características morfo-estruturais e da sua predisposição genética, o desenvolvimento das qualidades motoras e a estabilidade emocional do aluno deverão ser potenciadas ao longo da vida por uma postura de compromisso e entrega" ou seja, "[...] a determinação, a energia, o tempo e a paciência despendidos são direccionados para cada aspecto da preparação física, técnica e mental" (COGUMBREIRO, 2002, p.2)².

Encontramos justificativo para essa avaliação não só na expectativa de se acautelar um percurso o mais correto e satisfatório possível, garantindo mais e melhores performances ao nível da excelência no desempenho técnico e interpretativo, mas, também, na prevenção de futuras lesões e/ou entraves no percurso de formação e posterior carreira profissional.

$\mathrm{Na}$ expectativa da construção de um corpo "tecnicamente mapeado", cada vez mais próximo da excecionalidade, assumimos, aqui, a ideia da inevitabilidade das especializações em dança explicitadas por Xarez (2012), reforçando que, quanto maior for o grau de desenvolvimento, complexidade e exigência do repertório coreográfico, mais as especializações se tornam inevitáveis ou seja, tornam-se inevitáveis as exigências de um corpo disponível e apto técnica e artisticamente. Ou seja, um corpo capaz de, através da utilização do "arquivo" (LEPECKI, 2010) das suas múltiplas experiências e memórias (físicas, técnicas, sensoriais, sociais, artísticas...), dar maior e melhor resposta às solicitações cada vez mais diversificadas e exigentes do mercado da dança.

Como afirmaram Bauman e Carvalho,

O corpo arte é a manifestação final da dança, produto da aprendizagem e do treinamento do gesto técnico, que exige daquele que dança esforço, disciplina, dor e sacrifício na incessante busca da perfeição estética do movimento, e também da sensibilidade de expressar seus sentimentos por meio da arte da dança (BAUMAN; CARVALHO, 2005, p.68).

Nesta linha de pensamento, entendemos legítimo defender a formação de um bailarino (clássico ou contemporâneo) com capacidade e domínio sobre o seu corpo - enquanto instrumento afinado - com competências de criar novo vocabulário de movimento e capaz de responder de forma eficaz a novos desafios e em concordância com a pluralidade e mutabilidade das solicitações atuais, ou seja,acreditamos "que o dançarino profissional de hoje precisa desenvolver, durante a sua formação, um trabalho corporal o mais abrangente possível, para atender à amplitude de possibilidades da arte do movimento, expandindo qualquer limite técnico ou estético" (ROBATTO, 1994, p.275 apud CASTRO, 2007, p. 124).

1 COGUMBREIRO, Gabriela. $O$ aluno de dança: que perfil? In: FÓRUM DA DANÇA: A Dança na Arte e na Comunidade. Comunicação apresentada na $3^{\mathrm{a}}$ sessão, Tomar, 2002 [texto não publicado] 


\section{CONSIDERAÇÕES FINAIS}

Revisitámos ao longo deste ensaio alguns dos autores que refletem sobre o corpo nomeadamente sobre o corpo na dança, nas suas várias perspetivas.

Dessas leituras sobressaíram três ideias centrais. A primeira, a ideia do corpo dotado de competências (naturais, trabalhadas ou potenciadas) excecionais de movimentação/ação (postura, ritmo, força, flexibilidade, velocidade, equilíbrio, resistência, coordenação...) que 0 afastam do "corpo e do movimento normal".

A segunda, a ideia do corpo na dança enquanto entidade dinâmica, capaz de se mover em determinado espaço e num determinado tempo em que a incorporação de um conjunto de práticas (técnicas) permite-Ihes "cultivar e socializar, isto é, atribuir-Ihes uma forma e inscrevêlos socialmente" (FAZENDA, 2012, p. 67).

Por fim, a proficiência de um corpo (de bailarino(a)) que - ancorado na prática diária rigorosa e sistemática das técnicas de dança, na absorção e no registo corporal de códigos, regras e princípios - se transcende enquanto instrumento (simultaneamente físico, mecânico e químico), conjugando opções próprias de formação e salvaguardando espaços pessoais de desenvolvimento pessoal, artístico e de interação social.

Admitimos que as reflexões que se apresentam estão longe de serem consensuais e mantêm-se em aberto à espera de novas partilhas enriquecidas pela pluralidade, pela diversidade e flexibilidade dos corpos que vivem com a dança e através dos quais a dança sobrevive.

Em forma de conclusão subscrevemos, mais uma vez, pela clarividência e convergência com a reflexão apresentada, as palavras de Louppe (2012, p. 81) quando registou que "[...] na maior parte do tempo, diferentes corpos circulam, visíveis e invisíveis, no interior dos corpos dançantes, como vagas misteriosas, cujas referências corporais se confundem se sobrepõem" e que "[... ocorpo será, antes de mais, o que o pensamos, o que ele pensa por si e o lugar onde se aceita que ele nos leve" (LOUPPE, 2012, p. 88).

Almejamos a ideia de um "corpo pleno", enquanto instrumento intrínseco do bailarino/ intérprete, em que a técnica e a emoção se inscrevem em plena consonância, mas com a consciência de que "[...] nenhum corpo é igual a outro. Cada corpo traz à dança que materializa a sua identidade e a sua verdade" (LOURENÇO, 2014, p. 29).

Entendemos defender um corpo que assume importância, também, no ato criativo, principalmente se consideramos, no contexto da dança contemporânea, o papel do criadorintérprete.

Acrescentamos ao atrás referido que a técnica fará, assim, parte da identidade do bailarino, contribuirá para a sua definição, inscreverá nele características próprias que o definem como uno. Empossando-o, desta forma, enquanto agente, como alguém portador de um corpo "com assinatura própria".

Ou seja, sem privilegiar nenhuma técnica formal específica, estaremos a falar de um corpo treinado que se exprime, de um corpo que representa, de um corpo que se move no espaço e no tempo, de um corpo que dança.

E, voltando ao discurso de Barbora, "sonho mais quando danço do que quando durmo [...]. Dançar dói, mas dói mais quando estou parada” (RODRIGUES, 2015, p.11). 


\section{REFERÊNCIAS}

BATALHA, Ana Paula; XAREZ, Luís. Sistemática da dança I: projecto taxonómico. Cruz Quebrada: Edições FMH, 1999.

BAUMAN, Claudiana Donato; CAVALHO, Janice Guimarães, Técnica e expressividade: análise fenomenológica do corpo na dança. Motricidade, n. 1, p. 62-70, 2005. Disponível em: <http:// www.redalyc.org/articulo.oa?id=273021333008>. Acesso em: 29 dez. 2016.

CASTRO, Daniela Llopart.O aperfeiçoamento das técnicas de movimento em Dança. Movimento, v. 13, n. 1, p. 121-130, jan./abr. 2007.

FAZENDA, Maria José. Dança teatral: ideias, experiências, ações. Lisboa: Edições Colibri e Instituto Politécnico de Lisboa, 2012.

FERNANDES, João; GARCIA, Vítor. A hibrida relação entre as técnicas de dança contemporânea e a formação artística profissional.Revista Portuguesa de Educação Artística, n. 5, p.45-59, 2015. Disponível em: <http://citeweb.info/20150997956>. Acesso em: 29 dez. 2016.

FONSECA, António Manuel. Formação pessoal e social, valores profissionais e construção de projectos vocacionais. 1993. 121 f. Dissertação (Mestrado) - Ciências da Educação, Universidade de Aveiro, Aveiro, 1993.

FOSTER, Susan Leigh. Dancing bodies. In: CRARY, Jonathan et al. (Org.). Incorporation. New York: Urzonne, 1992. p. 480-495.

GLASSTONE, Richard. Better ballet. London: Kaye \& Ward, 1977.

HASKELL, Arnold.Ballet. Lisboa: Europa América, 1955.

INSTITUTO NACIONAL DE ESTATÍSTICA. Classificação portuguesa das profissões 2010. Lisboa: INE, 2011.

INSTITUTO PARA A QUALIDADE NA FORMAÇÃO. 0 sector das actividades artísticas, culturais e de espectáculo em Portugal.Lisboa: IQF, 2006.

KASSING Gayle; JAY Danielle Mary. Teaching beginning ballet technique. Champaign: Human Kinetics, 1998.

LAWSON, Joan. Ballet class: principles and practice. New York: Theatre Dut Book, 1988.

LEPECKI, André. The body as archive: will to re-enact and the afterlives of dances. Dance Research Journal, v. 42, n. 2, p. 28-48, 2010.

LOUPPE, Laurence. A poética da dança contemporânea. Lisboa: Orfeu Negro, 2012.

LOURENÇO, Frederico. Estética da dança clássica. Lisboa: Cotovia, 2014.

MACARA, Ana. Estudo da vivência do bailarino em cena: relações com traços de personalidade qualidades de interpretação. 1994. 105 f.Tese (Doutoramento Europeu em Motricidade Humana na especialidade de Dança) - Faculdade de Motricidade Humana, Cruz Quebrada, 1994. Disponível em: <http://dited.bn.pt/29981/index.html?cutepath=\%3Fid=MildNet>. Acesso em: 3fev.2017. 
MARTIN, John. La danse moderne, Paris: ACTES SUD, 1991.

MAUSS, Marcel. Sociologia e antropologia. São Paulo: Cosac e Naify, 2015.

MINDEN, Eliza Gaynor. The ballet companion.New York: Fireside, 2005.

MONTEIRO, Elisabete. As qualidades expresso-formais na técnica de dança: construção, validação e aplicação de um instrumento de avaliação. 1995. 89f.Tese (Doutoramento em Motricidade Humana na especialidade de Dança) - Faculdade de Motricidade Humana, Cruz Quebrada, 1995.

NASCIMENTO, Vanda Maria Santos. Os professores de técnicas de dança das escolas de educação artística vocacional em Portugal continental: caracterização do seu perfil académico e profissional e análise da sua prática docente. 2010. 92f. Tese (Doutoramento) - Universidade de Sevilha, Sevilha, 2010. Disponível em: <http://repositorio.ipl.pt/ bitstream/10400.21/2495/1/TD-2010NasVan preview.jpg>. Acesso em: 10 jan. 2017.

NETWORKDANCE.LA-LA-LA-Human-Steps audition. Disponível em: <http://www. networkdance.com/ballet-auditions/LA-LA-LA-HUMAN-STEPS-Audition/6472>. Acesso em: 15, dez. 2016.

NIELSEN, Eric Brandt; CILENTO, Wayne. Dance auditions: preparation, presentation, career planning. Florida: Princeton, 1984.

PORTUGAL. Decreto-Lei n.ำ 310/83, de 1 de julho de 1983. Estrutura o ensino das várias artes que tem vindo a ser ministrado no Conservatório Nacional. Diário da República, Lisboa, Ministério das Finanças e do Plano da Educação e da Reforma Administrativa, 1a série, n. 149, p.2387-2395, 1 jul. 1983.

RIBEIRO, António Pinto. Dança temporariamente contemporânea. Lisboa: Vega e Passagens, 1994.

RIBEIRO, António Pinto. Por exemplo a cadeira: ensaio sobre as artes do corpo. Lisboa:

Cotovia, 1997.

RODRIGUES, Tiago. Traduzir as tempestades. A Perna Esquerda de Tchaikovski: CNB, p.11, 2015. Disponível em: <https://issuu.com/cnbportugal/docs/cnb_pernaesquerda_desdobravel_issuu> Acesso em: 12,jul. 2017.

SIBONY, Daniel. Le corps e sa danse. Paris: Éditions Sevil, 1995.

TAYLOR, Jim; TAYLOR, Ceci. Psychology of dance. Champaign: Human Kinetics, 1995.

WALKER, Imogen J.; NORDIN-BATES, Sanna M.; REDDING, Emma. Talent identification and development in dance: a review of the literature. Research in Dance Education, v. 11, n. 3, p.165-189, 2010.

WARBURTON, Edward C. From talent identification to multidimensional assessment: toward new models of evaluation in dance education. Research in Dance Education, v. 3, n. 2, p. 103121, 2002.

XAREZ, Luís. Treino em dança: questões pouco frequentes. Cruz Quebrada: Edições FMH, 2012. 
